\title{
Investigation of the impact of anthropogenic heat flux within an urban land surface model and PILPS-urban
}

Article

Accepted Version

Best, M. J. and Grimmond, C. S. B. (2016) Investigation of the impact of anthropogenic heat flux within an urban land surface model and PILPS-urban. Theoretical and Applied Climatology, 126 (1). pp. 51-60. ISSN 0177-798X doi:

https://doi.org/10.1007/s00704-015-1554-3 Available at https://centaur.reading.ac.uk/51975/

It is advisable to refer to the publisher's version if you intend to cite from the work. See Guidance on citing.

Published version at: http://dx.doi.org/10.1007/s00704-015-1554-3

To link to this article DOI: http://dx.doi.org/10.1007/s00704-015-1554-3

Publisher: Springer

All outputs in CentAUR are protected by Intellectual Property Rights law, including copyright law. Copyright and IPR is retained by the creators or other copyright holders. Terms and conditions for use of this material are defined in the End User Agreement.

www.reading.ac.uk/centaur 
Central Archive at the University of Reading

Reading's research outputs online 
Investigation of the impact of anthropogenic heat flux within an Urban Land Surface model and PILPS-urban

MJ Best ${ }^{1,2}$, CSB Grimmond ${ }^{3,2}$

${ }^{1}$ Met Office, FitzRoy Road, Exeter, EX1 3PB, UK

e-mail: martin.best@metoffice.gov.uk

${ }^{2}$ King's College London, Department of Geography, London, WC2R 2LS, UK

${ }^{3}$ Department of Meteorology, University of Reading, Earley Gate, PO Box 243, Reading, RG6 6BB, UK

\section{Abstract}

Results from the first international urban model comparison experiment (PILPS-Urban) suggested that models which neglected the anthropogenic heat flux within the surface energy balance performed at least as well as models that include the source term, but this could not be explained. The analyses undertaken show that the results from PILPSUrban were masked by the signal from including vegetation, which was identified in PILPS-Urban as being important. Including the anthropogenic heat flux does give improved performance, but the benefit is small for the site studied given the relatively small magnitude of this flux relative to other terms in the surface energy balance. However, there is no further benefit from including temporal variations in the flux at this site. The importance is expected to increase at sites with a larger anthropogenic heat flux and greater temporal variations.

Keywords: Anthropogenic heat, JULES, Surface energy balance, Urban environment

\section{Introduction}

Numerical weather prediction (NWP) models have included surface processes for many years (e.g., Manabe, 1969), but it is only within the last decade that representations of urban areas have been included (e.g., Best, 2005, Lemonsu et al., 2009, Hamdi et al., 2014), even though urban energy balance models themselves have been developed over a much longer period (e.g., models evaluated by Ross and Oke, 1988, Masson, 2000, Martilli et al., 2002). The increasing resolution for NWP models has now reached the stage where urban areas can make up a large proportion of a grid-box, or in some instances actually be resolved. This has led to additional interest from this community to include a representation of urban areas within their modelling systems. Also, the move towards more integrated impacts for climate change has seen a move away from the post processing of urban areas from climate change signals, to including cities within the climate change simulations themselves (e.g., Oleson et al. 2008, McCarthy et al. 2010).

Unlike natural surfaces, the energy exchange within an urban environment includes additional source terms from the human activities (e.g., Sailor, 2011). These include the energy that is released from the heating of buildings and the emission of heat from vehicular transport. There is also a contribution from the metabolism of humans themselves, although this is typically small compared to the other sources (Sailor, 2011). Calculations of the total magnitude of this anthropogenic heat vary considerably between cities (e.g., Christen and Vogt, 2004, Offerle et al., 2005, Quah and Roth, 2011, Kotthaus and Grimmond, 2014), and between different areas of any particular city (e.g., Ichinose et al., 1999, Pigeon et al., 2007, Iamarino et al., 2012). In some locations the magnitude of the anthropogenic heat flux can be 
a substantial source term, similar to the daily mean solar forcing (e.g., Ichinose et al., 1999, Hamilton et al. 2009,

Iamarino et al. 2012).

A priori it would be expected that such an additional source term would need to be accounted for in any urban model. However, results from the first international urban model comparison project (PILPS-Urban) consistently suggested that models which do not include an anthropogenic heat flux performed at least as well as models that did include this flux (Grimmond et al., 2011, Best and Grimmond, 2013). These studies were not able to suggest the reasons for this and indicated that additional investigation is required.

Further to the results of these studies, Figure 1 shows the seasonal errors derived from the results of PILPS-Urban for the median model in each group, when the models are categorised by the complexity with which they represent the anthropogenic heat flux. These have been calculated using the methodology presented in Best and Grimmond (2013). The results show that the group of models that do not include the anthropogenic heat flux have the smallest root mean square errors (RMSE) for all four of the surface fluxes at all times of the year, compared to any of the other model groups that include this additional energy flux in various forms. In addition, the models without the anthropogenic heat flux also have the smallest bias for the sensible and latent heat fluxes, although they are the only group of models that have a negative bias in the sensible heat flux during the winter months.

Here we aim to understand the counter intuitive results from PILPS-Urban. To do this we use one of the models from the comparison which did not include any anthropogenic heat flux. We have rerun the simulations that were done for PILPS-Urban whilst introducing the additional source of energy to this model and analysed the subsequent impact on the results without this term, as submitted to the comparison.

\section{Methodology}

\subsection{Observations}

The observational site chosen for PILPS-Urban was Preston, a northern suburb of Melbourne, Australia. Details of the site are given in Coutts et al. (2007), and have also been summarised in the various analyses of PILPS-Urban results (Grimmond et al., 2011, Best and Grimmond, 2013, 2014). The site is described as urban climate zone (UCZ) 5, with moderately developed low density housing (Coutts et al., 2007). Two methods were used to determine the surface cover fractions over a $500 \mathrm{~m}$ radius with the average giving $45 \%$ building area, $5 \%$ concrete, $13 \%$ roads, $15 \%$ grass, $23 \%$ other vegetation and $1 \%$ other (Coutts et al., 2007), thus a total impervious surface of $62 \%$ and pervious of $38 \%$.

Observations of the radiative, sensible and latent heat fluxes were all undertaken whilst the net storage heat flux was determined as the residual of the surface energy balance. The net advective heat flux is difficult to determine and was assumed to be negligible, and the anthropogenic heat flux was derived using an inventory approach. Details of the instrumentation, sampling and averaging periods used by Coutts et al. (2007) are not discussed further here. 
To determine the anthropogenic heat flux Coutts et al. (2007), following Sailor and $\mathrm{Lu}$ (2004), consider the heat released from three different sources: vehicles, buildings (which is subsequently split further into electricity and natural gas), and human metabolism. The vehicular contribution were based on surveys undertaken during November $2002-$ October 2003 (Coutts et al., 2007) and the 2001 census population to estimate a distance travelled per person per day. To disaggregate to hourly values, the mean hourly traffic profile for U.S. cities from Hallenbeck et al. (1997) was invoked.

For building electricity half-hourly demand data were used, but only the fraction used for direct heating was accounted for. This is $43.1 \%$ of the total electricity usage, whilst the remaining $56.9 \%$ was used for refrigeration, lighting and appliances, for which heat is only a small by-product (and is thus neglected). For natural gas the diurnal heating profile was estimated using the diurnal variability in consumption which was modelled as a function of the daily range in temperature, using mean maximum and minimum temperatures occurring at 1700 and 0700 local solar time (LST) respectively, and linear interpolation.

The human metabolic rates, along with the day-time and night-time periods, were taken from Sailor and Lu (2004), i.e., $175 \mathrm{~W}$ between 0700 - 2100 LST and $75 \mathrm{~W}$ between 2300 - 0500 LST, respectively. During the transition periods (0600 and 2200 LST) a fixed value of $125 \mathrm{~W}$ was used, in contrast to Sailor and Lu (2004) who used linear interpolation between the day and night-time values. These metabolic rates were then used along with the population density to determine the contribution to the anthropogenic heat flux.

The contribution of the anthropogenic heat flux from human metabolism calculated by Coutts et al. (2007) is small compared to the other source terms, as seen in other studies (e.g., Grimmond, 1992; Sailor and Lu, 2004). For the other three components, the magnitude of their contribution is similar. The vehicle term has distinctive double peak during morning and afternoon rush hours which, as documented by Sailor and $\mathrm{Lu}$ (2004), but this is to be expected because the diurnal variations were determined from the same U.S. datasets. The natural gas term peaks in the morning at the time of minimum temperature (0700 LST) and has its smallest value in the afternoon at the time of maximum temperature (1700 LST), whereas the electricity term is fairly constant throughout the day. The resultant diurnal cycle for the anthropogenic heat flux has two peaks, but with the morning peak being greater and the afternoon peak (Coutts et al., 2007).

\subsection{Urban land surface model}

The model used in the current study was the Joint UK Land Environment Simulator (JULES, Best et al., 2011). JULES can be run off-line (as used within this study) or coupled to provide the land surface component within the Unified Model (UM, Cullen, 1993), which is used by the Met Office for weather forecasting and climate applications. Four sets of JULES results, in two configurations, were contributed to PILPS-Urban. These represented the urban fraction as a single bulk surface, or the roof surface and street canyons separately; namely the 1-tile (Best 2005) and 2-tile versions (Best et al. 2006). These two configurations were run by two modelling centres and ensured that the physical set up of the models was consistent, but the assumptions about the initial conditions, especially the soil moisture, were different. 
have important implications for the model performance. None of the four sets of JULES simulations included an anthropogenic heat flux.

Despite the differences in physical configuration and initial conditions between the four sets of JULES simulations, results from PILPS-Urban show that all of them perform well compared to other models (Figure 2, adapted from Grimmond et at., 2011), especially for the sensible and latent heat fluxes. Hence this is a good model to use to investigate the impact of including the additional anthropogenic heat flux.

For the simulations presented here, both the 1-tile and 2-tile versions of JULES were used, but with the initial soil moisture set to the same values as used for the dryer set of results contributed to PILPS-Urban.

To put the results for the impact of including the anthropogenic heat flux into context with other aspects of the physical system represented in the urban models, an additional simulation using JULES with no representation of vegetation was undertaken. Results from the previous studies of PILPS-Urban concluded that a representation of vegetation was critical in order to obtain good performance from the urban models, especially for the sensible and latent heat fluxes (Grimmond et al., 2010, 2011, Best and Grimmond, 2013, 2014). However, the method by which the vegetation is represented, i.e., though an independent surface (tile scheme) or interacting with the urban surface (integrated) was shown to be less important.

The JULES model included a tile scheme representation for vegetation in all four of the simulations submitted to PILPS-Urban, and the same representation has been used in all of the simulations with the anthropogenic heat flux. However, an additional simulation was completed with no anthropogenic heat flux and with the vegetation removed. This was done by setting the fraction of the vegetation surface to zero and re-scaling the urban surface fractions to sum to unity.

The JULES model was adapted to include the anthropogenic heat flux as an additional term in its surface energy balance:

$$
C \frac{\partial T}{\partial t}=Q^{*}-Q_{H}-Q_{E}-\Delta Q_{S}+Q_{F}
$$

where $C$ is the areal heat capacity of the surface, $T$ is the surface temperature, $Q *$ is the net all-wave radiation, $Q_{H}$ is the turbulent sensible heat flux, $Q_{E}$ is the latent heat flux, $\Delta Q_{S}$ is the net storage heat flux and $Q_{F}$ is the anthropogenic heat flux.

The anthropogenic heat flux can hence be considered as an additional source term to the surface energy balance, equivalent to additional radiative flux forcing. As such it will lead to an increase surface temperature with associated larger values of the sensible and latent heat fluxes, the net storage heat flux and the outgoing longwave radiation. The net impact on an atmospheric model to the inclusion of anthropogenic heat flux would be to increase the heat, moisture and longwave radiative flux boundary conditions from the surface. 
The anthropogenic heat flux was specified at every time-step of the model run, based upon the observed values of the anthropogenic heat flux. By using the observed values, the analysis removes the impact of using a scheme to represent the flux which would inevitably have its own inaccuracies. Hence we can identify the true impact of including the anthropogenic heat flux.

For the 1-tile version, the anthropogenic heat flux was applied to just the urban surface energy balance. However, for the 2-tile version there is more flexibility regarding the addition of the flux. It can be added to the canyon surface energy balance only, the roof surface energy balance or to both the canyon and the roof surface energy balances. To understand the full impact of the anthropogenic heat flux on the JULES simulations, the 2-tile version was run in all three configurations. The anthropogenic heat flux applied to each surface was scaled to ensure that the total flux integrated over all surfaces is equal to the observed values.

In addition to investigating the impact of including the anthropogenic heat flux, the impact of the temporal variation in the flux is considered. Four methods were used (Fig. 3a-d), namely:

a) The average value of the period of the observations: constant (i.e., no temporal variation)

b) Monthly mean values, constant diurnal cycle, causing a step change between consecutive months

c) Average diurnal cycle over the entire observational period, constant variation between months

d) Monthly mean diurnal cycle, with variations between months (estimated $Q_{F}$ data, Coutts et al., 2007)

The latter is the full temporal resolution of $\mathrm{Q}_{\mathrm{F}}$ available. Note there are no differences in diurnal cycle between days within the same month given the methodology used to determine the observed values; i.e., no response to meteorological conditions or human behavior (e.g., days of the week).

The mean anthropogenic heat flux in the observational dataset is $11 \mathrm{~W} \mathrm{~m}^{-2}$, which is assumed to occur only on the built land cover in JULES (i.e., not applied to vegetation or bare soil surfaces), and so requires a value of $17 \mathrm{~W} \mathrm{~m} \mathrm{~m}^{-2}$ to be used in JULES. This corresponds to a diurnal maximum of $26 \mathrm{~W} \mathrm{~m}^{-2}$ and a minimum of $10 \mathrm{~W} \mathrm{~m}^{-2}$. Figure $3 \mathrm{e}$ shows the average diurnal cycle over the observational period, along with the diurnal cycles for the months with the maximum and minimum values. This figure shows two important aspects for understanding the results presented here. Firstly, the magnitude of the flux is small compared to the average of the other terms in the surface energy balance $\left(\mathrm{Q}^{*}=83 \mathrm{~W} \mathrm{~m}^{-2}\right.$, $\mathrm{Q}_{\mathrm{H}}=40 \mathrm{~W} \mathrm{~m}^{-2}, \mathrm{Q}_{\mathrm{E}}=34 \mathrm{~W} \mathrm{~m}^{-2}$ and $\left.\Delta \mathrm{Q}_{\mathrm{S}}=20 \mathrm{~W} \mathrm{~m}^{-2}\right)$, and in particular to the mean incoming shortwave radiation $(\mathrm{K} \downarrow=$ $168 \mathrm{~W} \mathrm{~m}^{-2}$ ). Secondly, the minimum values in the diurnal cycle occur during the night-time hours, when the sensible heat flux is small.

\subsection{Analysis methods}

The mean bias error (MBE) and root mean square error (RMSE) for $\mathrm{Q}^{*}, \mathrm{Q}_{\mathrm{H}}$ and $\mathrm{Q}_{\mathrm{E}}$ for each of the simulations are presented in Figure 4, for all data points and separately for the night-time values only (defined by $\mathrm{K} \downarrow=0.0 \mathrm{~W} \mathrm{\textrm {m } ^ { - 2 }}$ ). The statistics for the net storage heat flux are not shown as this is taken to be the residual of the energy balance in the observations and as such aggregates the observational errors. To calculate these statistics, any time-steps with missing observational data for any flux are omitted from the analysis. This is to ensure that the results are consistent between the 
fluxes, and with the methodology that was adopted in PILPS-Urban by Grimmond et al. (2011) and Best and Grimmond $(2013,2014)$.

\section{Results}

Figure 4 shows that the JULES simulations that include the anthropogenic heat flux have better performance (smaller MBE and RMSE) for the sensible heat flux, compared to the simulations without the anthropogenic heat flux (as submitted to PILPS-Urban). This holds for the analysis using all of the data and using the night-time data only. The latent heat flux has a very small increase in the positive bias over all of the data and a decrease in the negative bias for the night-time only data, but virtually no change to the RMSE. However, for $\mathrm{Q}^{*}$ there is an increase in the MBE for both all data and the night-time data and a corresponding increase in the RMSE.

The increase in negative bias for the night-time results for $\mathrm{Q} *$ are a result from the higher surface temperatures leading to more outgoing longwave radiation. However, since $\mathrm{Q}_{\mathrm{H}}$ still has a negative bias when $\mathrm{Q}_{\mathrm{F}}$ is included, this suggests that the relation between the radiative surface temperature and the thermodynamic temperature within JULES is not optimal and could be improved.

The results show that for the anthropogenic heat flux with temporal variations there is little impact on all three of the fluxes (Figure 4), with only small differences in either the MBE or the RMSE. Hence for these simulations, including the average value of the anthropogenic heat flux is more important than having time varying values, either diurnally of monthly. However, it should be noted that for this study only the mean monthly variations in $\mathrm{Q}_{\mathrm{F}}$ are available and not the true temporal variability that depends on the meteorological conditions and human behavior, such as weekdays versus weekends.

All of the 2-tile versions perform better than the equivalent 1-tile version for Q* and $\mathrm{Q}_{\mathrm{H}}$ for both MBE and RMSE for all data and night-time data only. The only exception is for the MBE in $\mathrm{Q}_{\mathrm{H}}$ with the simulations that do not include vegetation. There is no difference between the 1-tile and 2-tile versions for $\mathrm{Q}_{\mathrm{E}}$ for either the MBE or the RMSE, except for the night-time MBE for the 2-tile version with the anthropogenic heat flux only applied to the canyon surface, which has a slightly larger negative bias.

There are also differences with the 2-tile version of JULES for $\mathrm{Q}^{*}$ and $\mathrm{Q}_{\mathrm{H}}$ when considering the surfaces over which the anthropogenic heat flux are implemented. The simulations with the anthropogenic heat flux applied to just the canyon surface have noticeably smaller MBE than the other simulations for both all data and night-time only data, but these improvements are not evident in the RMSE apart from the night-time data for $\mathrm{Q}_{\mathrm{H}}$ which has a very small improvement. Consistent with these results, we find that not applying the anthropogenic heat flux to the canyon tile (i.e., applying it only to the roof tile) leads to larger MBE and RMSE, particularly for the sensible heat flux.

Despite the improvements that can be detected from the model simulations that include the anthropogenic heat flux, these are far smaller than the improvements that are obtained from including a representation of vegetation, especially for the RMSE for all of the data. These results are robust over all of the sets of simulations. 
The maximum values of the anthropogenic heat flux occur in the winter months (Fig. 3d), when the diurnally averaged sensible heat flux is at its lowest values. Hence we might expect to see a larger impact from the anthropogenic heat flux on $\mathrm{Q}_{\mathrm{H}}$ at this time of the year. Seasonal variations of 60 day means in the results for the 2-tile version of JULES, with the anthropogenic heat flux applied only to the canyon energy balance, are shown in Figure 5 for the night-time. This figure shows the mean flux, MBE and the RMSE for all of the surface fluxes and is equivalent to the analysis presented in Best and Grimmond (2013) for all of the models in PILPS-Urban. For both the day-time (not shown) and night-time results (Fig. 5), the seasonal cycle of the anthropogenic heat flux generally makes no difference to the improvement of the model in terms of MBE for any of the fluxes. The results are consistent across all of the months, with the only exception being a slight improvement to the MBE of $\sim 1.5 \mathrm{~W} \mathrm{~m}^{-2}$ for the night-time $\mathrm{Q}_{\mathrm{H}}$ during June/July (JJ) compared to the summer months. However, there is a slightly larger improvement in the RMSE for $\mathrm{Q}_{\mathrm{H}}\left(\sim 3 \mathrm{~W} \mathrm{~m}^{-2}\right)$ in both the day-time (not shown) and night-time (Fig. 5) during the winter months (JJ) compared to not including the anthropogenic heat flux. For nocturnal data this improvement results from the RMSE not increasing by as much as for the results from the model without anthropogenic heat flux.

For the net storage heat flux, there is a slight improvement in both the MBE and RMSE during the day-time from including the anthropogenic heat flux (not shown), but a degradation in both statistics for the night-time (Fig. 5). These changes to both MBE and RMSE are consistent throughout the seasonal cycle.

As well as the anthropogenic heat flux having larger impacts at certain times within the seasonal cycle, we might expect the impact on the surface fluxes to vary during the diurnal cycle, especially when $Q_{н}$ has its smallest values (i.e., during the night-time). However, an equivalent figure to Fig. 1 of Best and Grimmond (2013), for the average diurnal cycle for each 60 day period of the seasonal cycle, shows that the impact on the diurnal cycle for all of the surface fluxes is small (not shown). At the scale of the range of the diurnal cycle, the differences in the various model simulations that include the anthropogenic heat flux are not discernible from those without an anthropogenic heat flux.

Focusing on just the night-time part of the diurnal cycle (Fig. 6), results show that for this period there are some noticeable differences in the sensible and net storage heat fluxes between the model simulations. All of the JULES runs that include $\mathrm{Q}_{\mathrm{F}}$ are almost indistinguishable from each other, but for the sensible heat flux they are clearly closer to the observed values than the JULES run that excludes $\mathrm{Q}_{\mathrm{F}}$ (hence reducing the bias, Fig. 6). This reduced negative bias in the sensible heat flux from including $\mathrm{Q}_{\mathrm{F}}$ ranges from a minimum of $4.8 \mathrm{~W} \mathrm{~m}^{-2}$ in the summer to a maximum of $7.3 \mathrm{~W}$ $\mathrm{m}^{-2}$ in the winter.

For the net storage heat flux, there is a reduction in the magnitude of the negative flux during the night-time from the runs with $\mathrm{Q}_{\mathrm{F}}$ compared to the run without $\mathrm{Q}_{\mathrm{F}}$. The results for the JULES simulation without an anthropogenic heat flux have only a small bias in the net storage heat flux at night-time over most of the seasonal cycle. So subsequent changes to the night-time values in the net storage heat flux from implementing an anthropogenic heat flux into JULES introduces a more notable positive bias at all times of the year (results are further from the observations compared to the 


\section{Conclusions}

The JULES model, one of the better performing models in PILPS-Urban (especially for $\mathrm{Q}_{\mathrm{H}}$ and $\mathrm{Q}_{E}$ ) did not include any representation of the anthropogenic heat flux. Hence it is a good tool to investigate if the inclusion of $\mathrm{Q}_{\mathrm{F}}$ could improve the model performance still further.

The results from the runs presented here to investigate this have shown that there is an improvement in both the MBE and RMSE throughout the seasonal cycle from including the anthropogenic heat flux in JULES. Whilst the improvement to the MBE is fairly constant throughout the year for the day-time results, the improvement in the nighttime MBE and the day-time MBE and RMSE is greater in the winter months, when $\mathrm{Q}_{\mathrm{H}}$ has its smallest average diurnal values, compared to the summer months.

A positive impact is also evident for $\mathrm{Q}_{\mathrm{H}}$ during the night-time, with the consistent negative bias from the simulations without $\mathrm{Q}_{\mathrm{F}}$ reduced when the $\mathrm{Q}_{\mathrm{F}}$ term is included in the surface energy balance of JULES. These changes also lead to a greater reduction in the night-time RMSE in the winter months than in the summer, as might be expected since $\mathrm{Q}_{\mathrm{H}}$ has its lowest values.

The impact of including $\mathrm{Q}_{\mathrm{F}}$ on $\mathrm{Q}^{*}$ is not so beneficial, leading to a slight degradation in both the MBE and RMSE. However, this negative impact of $\mathrm{Q}_{\mathrm{F}}$ within the JULES simulations is more indicative of issues with the radiation balance rather than a direct influence of $\mathrm{Q}_{\mathrm{F}}$ itself. It is possible that if the radiation issues within JULES were improved, the impact of including $\mathrm{Q}_{\mathrm{F}}$ might also give beneficial results for $\mathrm{Q}^{*}$.

There are also negative impacts on the errors for the net storage heat flux, with both the MBE and RMSE being degraded when $\mathrm{Q}_{\mathrm{F}}$ is included in the simulations. The negative bias in $\Delta \mathrm{Q}_{\mathrm{S}}$ during the day-time throughout the year, along with the positive night-time bias, suggests that insufficient energy is being stored during the day-time and subsequently released during the night-time. This is consistent with the results presented by Best and Grimmond (2014) who suggested that urban models have energy partitioning issues in general between $\mathrm{Q}_{\mathrm{H}}$ and $\Delta \mathrm{Q}_{\mathrm{s}}$.

Whilst the inclusion of the anthropogenic heat flux leads to some improvements within the simulations, the magnitude of these improvements is small, even to the extent that it is difficult to identify the changes when looking at the full diurnal cycle of the fluxes. The magnitude of the anthropogenic heat flux within the observational dataset has an average value of $11 \mathrm{~W} \mathrm{~m}^{-2}$, which is typical of suburban areas. This could suggest that $\mathrm{Q}_{\mathrm{F}}$ is not significant in these environments, especially since the minimum values of $\mathrm{Q}_{\mathrm{F}}$ occur at similar times during the night to the smallest values of the sensible heat flux. However, the temporal variations in $\mathrm{Q}_{\mathrm{F}}$ used in this study were only the mean monthly variations and do not take into account the meteorological conditions, or human behavior such as weekday and weekend activities, hence the actual variations in $\mathrm{Q}_{\mathrm{F}}$ might have a greater impact. In addition, for urban areas in colder climates, $\mathrm{Q}_{\mathrm{F}}$ could contribute a relatively larger fraction to the surface energy balance, due to the smaller size of radiative fluxes, and hence be more significant. The flux is also known to be much greater in dense, urban centres (e.g., Ichinose et al., 1999). 
The seasonal variations in $\mathrm{Q}_{\mathrm{F}}$ are also small, which explains why the increased positive impact from including the flux during the winter months is also small. The small magnitude and diurnal cycle of the anthropogenic heat flux at this site could well be responsible for this result. It is likely that at sites with large variations in both the diurnal and seasonal cycles in $\mathrm{Q}_{\mathrm{F}}$ there will be additional benefits from resolving the temporal behavior of the anthropogenic heat flux.

The impact of including $Q_{F}$ is much smaller on both the MBE and RMSE for all of the data and night-time data only, than including a representation of vegetation for the site. Again this result is influenced by the relatively small magnitude of the anthropogenic heat flux. However, nearly all of the models that neglected $\mathrm{Q}_{\mathrm{F}}$ in PILPS-Urban did include a representation of vegetation, whilst other categories that included $\mathrm{Q}_{\mathrm{F}}$ contained a greater proportion of models that neglected vegetation. Hence the counter intuitive results presented in the PILPS-Urban, suggesting that the group of models that did not include the anthropogenic heat flux performed at least as well as the models that did include this flux, were being influenced by the treatment of vegetation within these models.

From the results presented in this study we can conclude that a representation of the anthropogenic heat flux is important for urban models and can lead to improved results. Moreover, the influence of the anthropogenic heat flux is likely to be greater at sites with a larger flux, increasing the need for the urban models to include this term in their surface energy balance.

Acknowledgements M. Best was supported by the Joint DECC/Defra Met Office Hadley Centre Climate Programme (CA01101). Grimmond acknowledges support from Newton Fund/Met Office CSSP-China. Funds to support PILPS-

345 Urban were provided by the Met Office (P001550). We would like to thank Andrew Coutts, Jason Beringer and Nigell

346 Tapper for allowing their data to be used for the comparison. We would also like to thank Maggie Hendry and Mariana Gouvea for undertaking the JULES simulations for PILPS-Urban, and everyone else who contributed model simulations to the comparison. 
Best MJ (2005) Representing urban areas within operational numerical weather prediction models. Boundary-Layer Meteorol 114: 91-109

Best MJ, CSBGrimmond CSB, Villani MG (2006) Evaluation of the urban tile in MOSES using surface energy balance observations. Boundary- Layer Meteorol 118: 503-525

Best MJ, Pryor M, Clark DB, Rooney GG, Essery RHL, Ménard CB, Edwards JM, Hendry MA, Porson A, Gedney N, Mercado LM, Sitch S, Blyth E, Boucher O, Cox PM, Grimmond CSB, Harding RJ (2011) The Joint UK Land Environment Simulator (JULES), Model description - Part 1: Energy and water fluxes. Geosci Model Dev 4: 677699

Best MJ, Grimmond CSB (2013) Analysis of the seasonal cycle within the first international urban land surface model comparison. Boundary-Layer Meteorol 146: 421-446. doi: 10.1007/s10546-012-9769-7

Best MJ, Grimmond CSB (2014) Importance of initial state and atmospheric conditions for urban land surface models performance. Urban Climate. doi:10.1016/j.uclim.2013.10.006

Christen A, Vogt R (2004) Energy and radiation balance of a Central European City. Int J Climatol 24: 1395-1421.

Coutts AM, Beringer J, Tapper NJ (2007) Impact of increasing urban density on local climate: Spatial and temporal variations in the surface energy balance in Melbourne, Australia. J Appl Meteorol 47: 477-493

Cullen M J P (1993) The unified forecast/climate model, Meteorol. Mag., 122, 81-94.

Grimmond CSB, Blackett M, Best MJ, Barlow J, Baik J-J, Belcher SE, Bohnenstengel SI, Calmet I, Chen F, Dandou A, Fortuniak K, Gouvea ML, Hamdi R, Hendry M, Kawai T, Kawamoto Y, Kondo H, Krayenhoff ES, Lee S-H, Loridan T, Martilli A, Masson V, Miao S, Oleson K, Pigeon G, Porson A, Ryu Y-H, Salamanca F, Shashua-Bar L, Steeneveld G-J, Trombou M, Voogt J, Young D, Zhang N (2010) The international urban energy balance models comparison project: first results from phase 1. J Appl Meteorol Climatol 49: 1268-1292. doi:10.1175/2010JAMC2354.1

Grimmond CSB, Blackett M, Best MJ, Baik J-J, Belcher SE, Beringer J, Bohnenstengel SI, Calmet I, Chen F, Coutts A, Dandou A, Fortuniak K, Gouvea ML, Hamdi R, Hendry M, Kanda M, Kawai T, Kawamoto Y, Kondo H, Krayenhoff ES, Lee S-H, Loridan T, Martilli A, Masson V, Miao S, Oleson K, Ooka R, Pigeon G, Porson A, Ryu Y-H, Salamanca F, Steeneveld G-J, Trombou M, Voogt J, Young D, Zhang N (2011) Initial results from phase 2 of the international urban energy balance model comparison. Int J Climatol 30: 244-272. doi:10.1002/joc.2227.

Hallenbeck M, Rice M, Smith B, Cornell-Martinez C, Wilkinson J (1997) Vehicle volume distribution by classification. Washington State Transportation Center, University of Washington, 54 pp. [Available from Washington State Transportation Center, University of Washington, 1107 NE 45 ${ }^{\text {th }}$ St. Suite 535, Seattle WA 98105]

Hamdi R, Degrauwe D, Duerinckx A, Cedilnik J, Costa V, Dalkilic T, Essaouini K, Jerczynki M, Kocaman F, Kullmann L, Mahfouf J-F, Meier F, Sassi M, Schneider S, Váňa F, Termonia P (2014) Evaluating the performance of SURFEXv5 as a new land surface scheme for the ALADINcy36 and ALARO-0 models. Geosci. Model Dev. 7: 23-39. doi: 10.5194/gmd-7-23-2014.

Hamilton IG, Davies M, Steadman P, Stone A, Ridley I, Evans S (2009) The significance of the anthropogenic heat emissions of London's buildings: A comparison against captured shortwave solar radiation. Building and Environ. 44, 807-817. 1970-2025. Int J Climatol 32: 1754-1767. doi:10.1002/joc.2390 
Ichinose T, Shimodozono K, Hanaki K (1999) Impact of anthropogenic heat on urban climate in Tokyo. Atmos Environ 33: 3897-3909

Kotthaus S, Grimmond CSB (2014) Energy exchange in a dense urban environment - Part I: Temporal variability of long-term observations in central London. Urban Climate. doi:10.1016/j.uclim.2013.10.002

Lemonsu A, Belair S, Mailhot J (2009) The new Canadian urban modelling system: Evaluation for two cases from the joint urban 2003 Oklahoma City experiment. Boundary- Layer Meteorol 113: 47-70. doi: 10.1007/s10546-0099414-2.

Manabe S (1969) Climate and the ocean circulation: 1, The atmospheric circulation and the hydrology of the earths' surface. Mon Wea Rev 97: 739-805

Martilli A, Clappier A, Rotach MW (2002) An urban surface exchange parameterisation for mesoscale models. Boundary-Layer Meteorol 104: 261-304

Masson V (2000) A physically-based scheme for the urban energy budget in atmospheric models. Boundary-Layer Meteorol 41: 1011-1026

McCarthy MP, Best MJ, Betts RA (2010) Climate change in cities due to global warming and urban effects. Geophys Res Letters 37: L09705. doi:10.1029/2010GL042845

Offerle B, Grimmond CSB, Fortuniak K (2005) Heat storage and anthropogenic heat flux in relation to the energy balance of a central European city centre. Int J Climatol 25: 1405-1419. doi:10.1002/joc.1198

Oleson KW, Bonan GB, Feddema J, Vertenstein M, Grimmond CSB (2008) An urban parameterization for a global climate model: 1. Formulation and evaluation for two cities. J Appl Meteorol Climatol 47: 1038-1060

Pigeon G, Legain D, Durand P, Masson V, (2007) Anthropogenic heat release in an old European agglomeration (Toulouse, France). Int J Climatol 27: 1969-1981

Quah AKL, Roth M (2011) Diurnal and weekly variation of anthropogenic heat emissions in a tropical city, Singapore.

416 Ross SL, Oke TR (1988) Tests of three urban energy balance models. Boundary-Layer Meteorol 44: 73-96 environment. Int J Climatol 31: 189-199. 


\section{Figure captions}

Fig. 1: Median of the mean modelled flux, mean bias error (MBE), and root mean square error (RMSE) for the surface fluxes from all models within PILPS-Urban, determined for two month periods, for the models classified by their representation of the anthropogenic heat flux (None - $Q_{F}$ neglected, Prescribed - $Q_{F}$ prescribed during model simulation, Internal Temperature - models use an internal building temperature to calculate $\mathrm{Q}_{\mathrm{F}}$, Prescribed + Internal T combination of prescribed $\mathrm{Q}_{\mathrm{F}}$ (e.g. vehicular component) and internal building temperature to calculate additional $\mathrm{Q}_{\mathrm{F}}$, Modelled - all aspects of $\mathrm{Q}_{\mathrm{F}}$ modelled). Note the scales are different for each flux. For details of PILPS-Urban see section 2, and for method of analysis see Best and Grimmond (2013).

Fig. 2: Ranked model performance for stage 4 of PILPS-Urban, for each of the surface fluxes. The four sets of results from the JULES model are highlighted. These were generated from the 1- and 2-tile configurations, each run with low (dry) and high (wet) initial soil moisture. Adapted from Grimmond et al. (2011).

Fig. 3: Temporal variations in the anthropogenic heat flux applied to the urban surface fraction for the model simulations: (a) mean for observational period, (b) mean monthly value, (c) mean diurnal cycle for observational period, (d) monthly mean diurnal cycle, (e) mean diurnal cycle for observational period applied to the urban surface fraction (dashed line), with the average diurnal cycles for the months with maximum and minimum values (solid lines).

Fig. 4: MBE (a-c) and RMSE (d-f) for net all-wave radiation (a,d), sensible heat flux $(b, e)$ and latent heat flux (c,f), for both day- (filled) and night-time (hollow), for all implementations of temporal variation in the anthropogenic heat flux, and simulations without vegetation. Results are presented for the 1 and 2 tile configurations with the anthropogenic heat flux applied to only the canyon, only the roof, or both canyon and roof. Note the scales are different for each flux.

Fig. 5: Nocturnal mean modelled flux (row 1), MBE (row 2), and RMSE (row 3) for the surface fluxes determined for two month periods.

Fig. 6: Mean diurnal cycle for each 60-day period throughout the seasonal cycle, scaled to focus on the night-time 


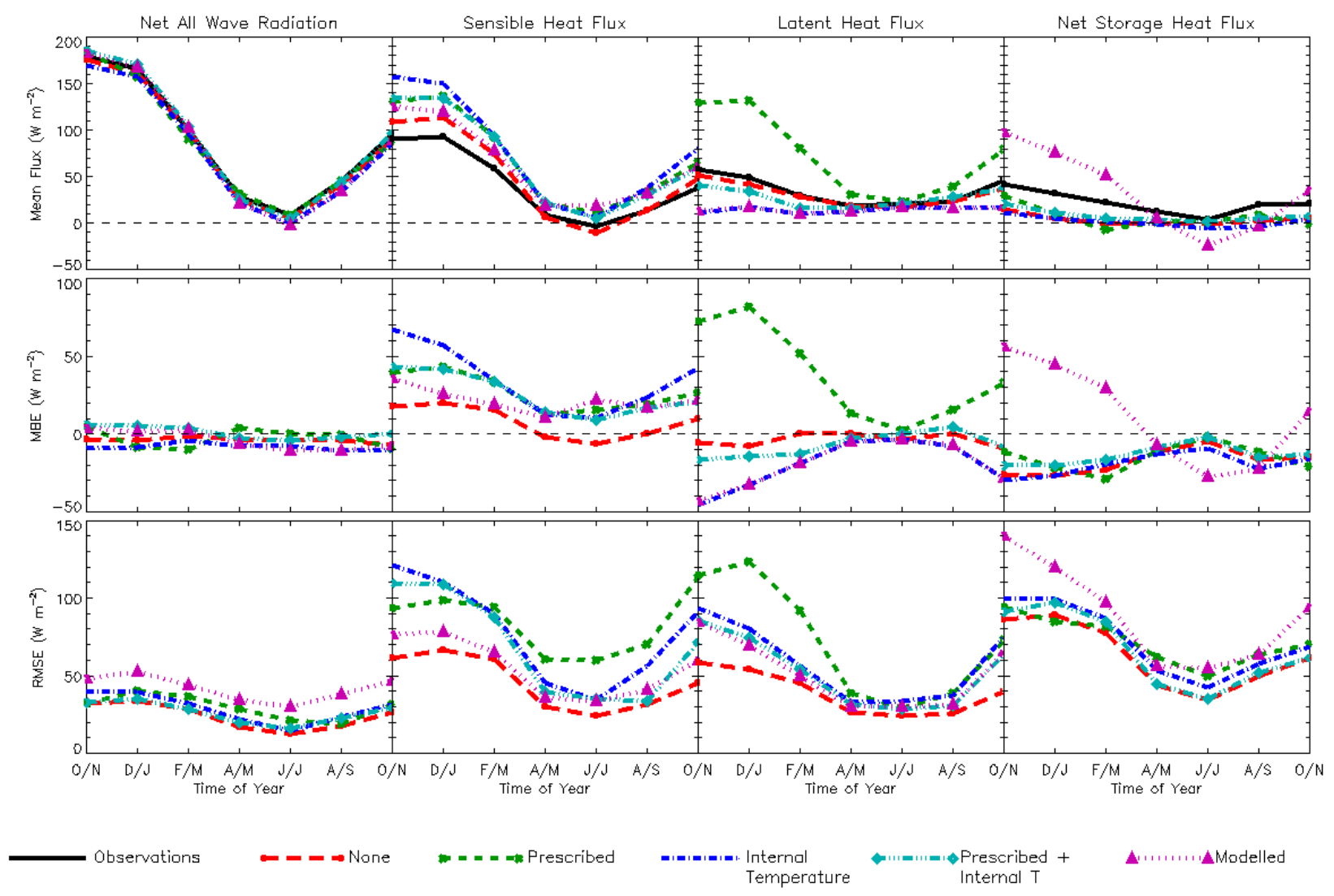

454 Fig. 1: Median of the mean modelled flux, mean bias error (MBE), and root mean square error (RMSE) for the surface

455 fluxes from all models within PILPS-Urban, determined for two month periods, for the models classified by their

456 representation of the anthropogenic heat flux (None - $\mathrm{Q}_{\mathrm{F}}$ neglected, Prescribed - $\mathrm{Q}_{\mathrm{F}}$ prescribed during model simulation,

457 Internal Temperature - models use an internal building temperature to calculate $\mathrm{Q}_{\mathrm{F}}$, Prescribed + Internal T -

458 combination of prescribed $\mathrm{Q}_{\mathrm{F}}$ (e.g. vehicular component) and internal building temperature to calculate additional $\mathrm{Q}_{\mathrm{F}}$,

459 Modelled - all aspects of $\mathrm{Q}_{\mathrm{F}}$ modelled). Note the scales are different for each flux. For details of PILPS-Urban see

460 section 2, and for method of analysis see Best and Grimmond (2013). 

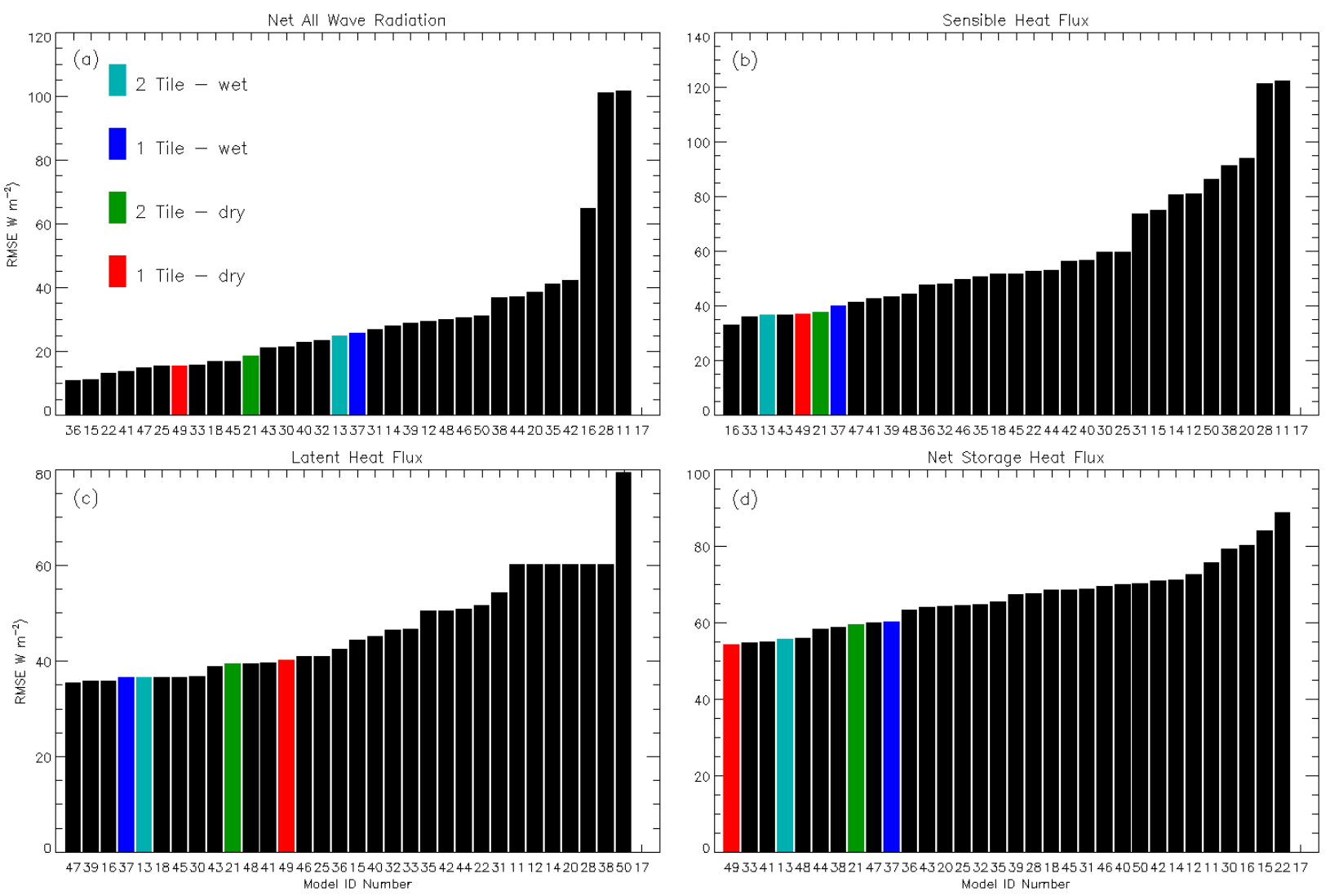

Fig. 2: Ranked model performance for stage 4 of PILPS-Urban, for each of the surface fluxes. The four sets of results 466 from the JULES model are highlighted. These were generated from the 1- and 2-tile configurations, each run with low 467 (dry) and high (wet) initial soil moisture. Adapted from Grimmond et al. (2011). 

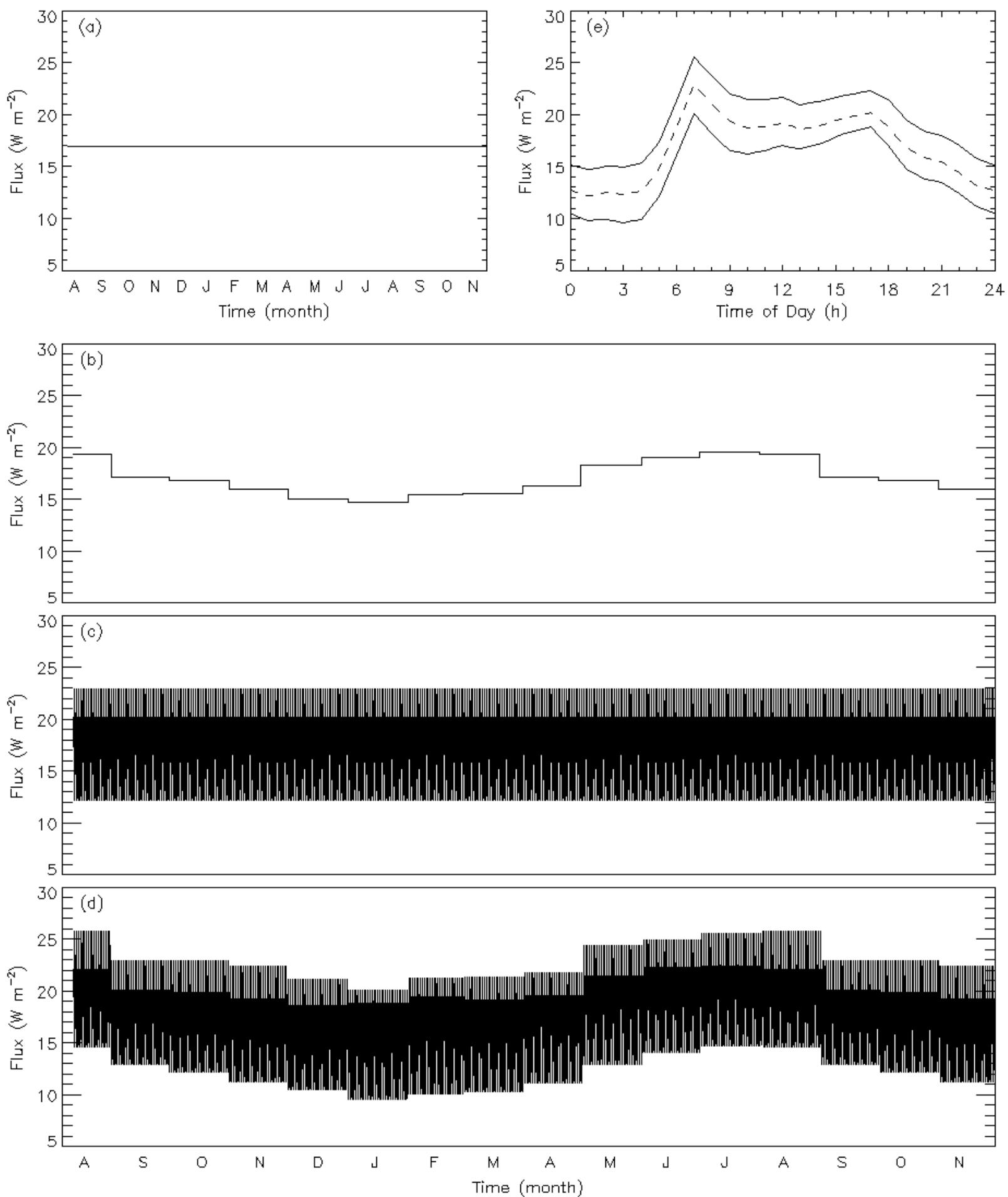

469 470

Fig. 3: Temporal variations in the anthropogenic heat flux applied to the urban surface fraction for the model simulations: (a) mean for observational period, (b) mean monthly value, (c) mean diurnal cycle for observational period, (d) monthly mean diurnal cycle, (e) mean diurnal cycle for observational period applied to the urban surface fraction (dashed line), with the average diurnal cycles for the months with maximum and minimum values (solid lines). 

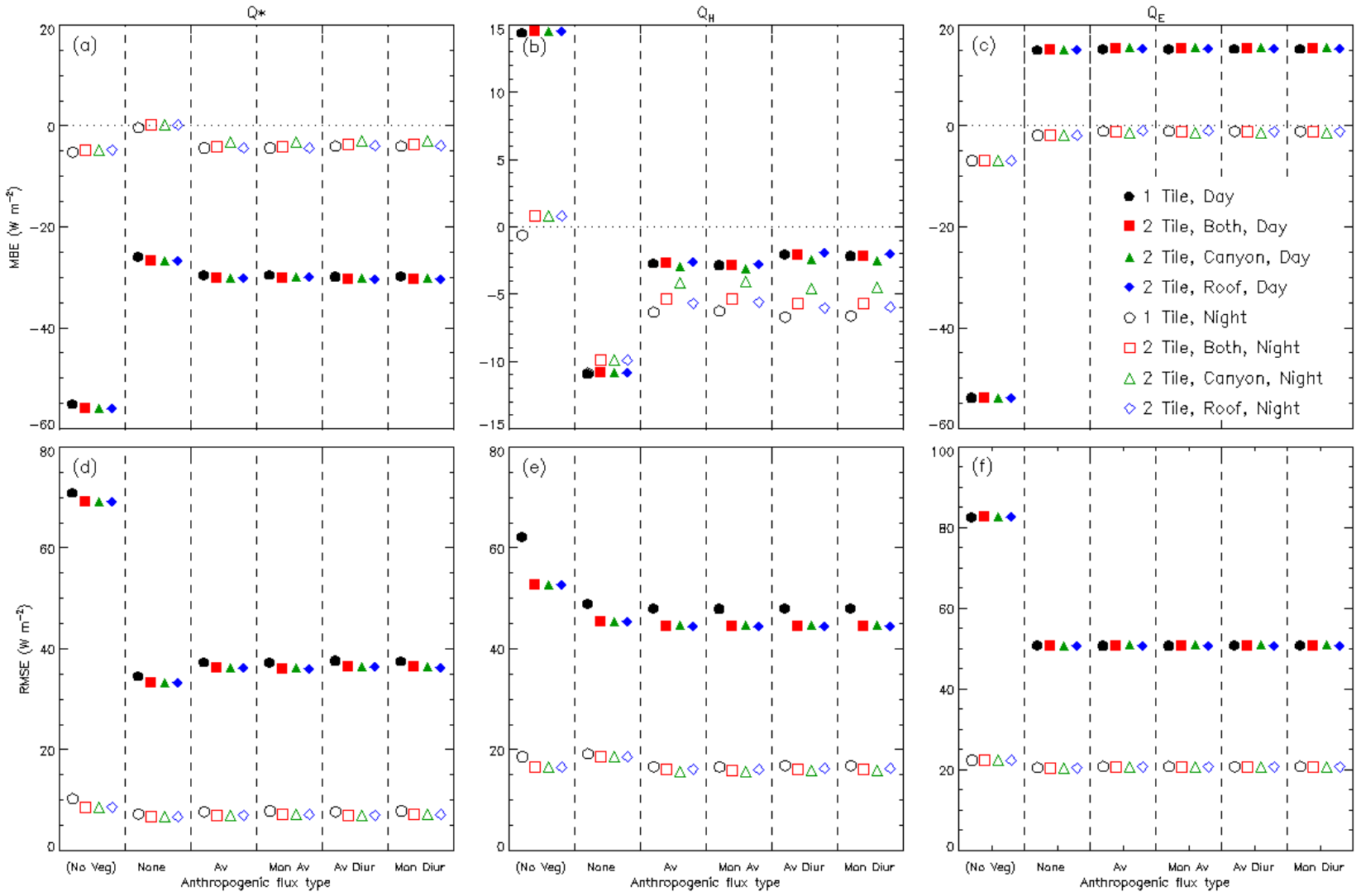

Fig. 4: MBE (a-c) and RMSE (d-f) for net all-wave radiation (a,d), sensible heat flux $(b, e)$ and latent heat flux (c,f), for both day- (filled) and night-time (hollow), for all implementations of temporal variation in the anthropogenic heat flux, and simulations without vegetation. Results are presented for the 1 and 2 tile configurations with the anthropogenic heat flux applied to only the canyon, only the roof, or both canyon and roof. Note the scales are different for each flux. 


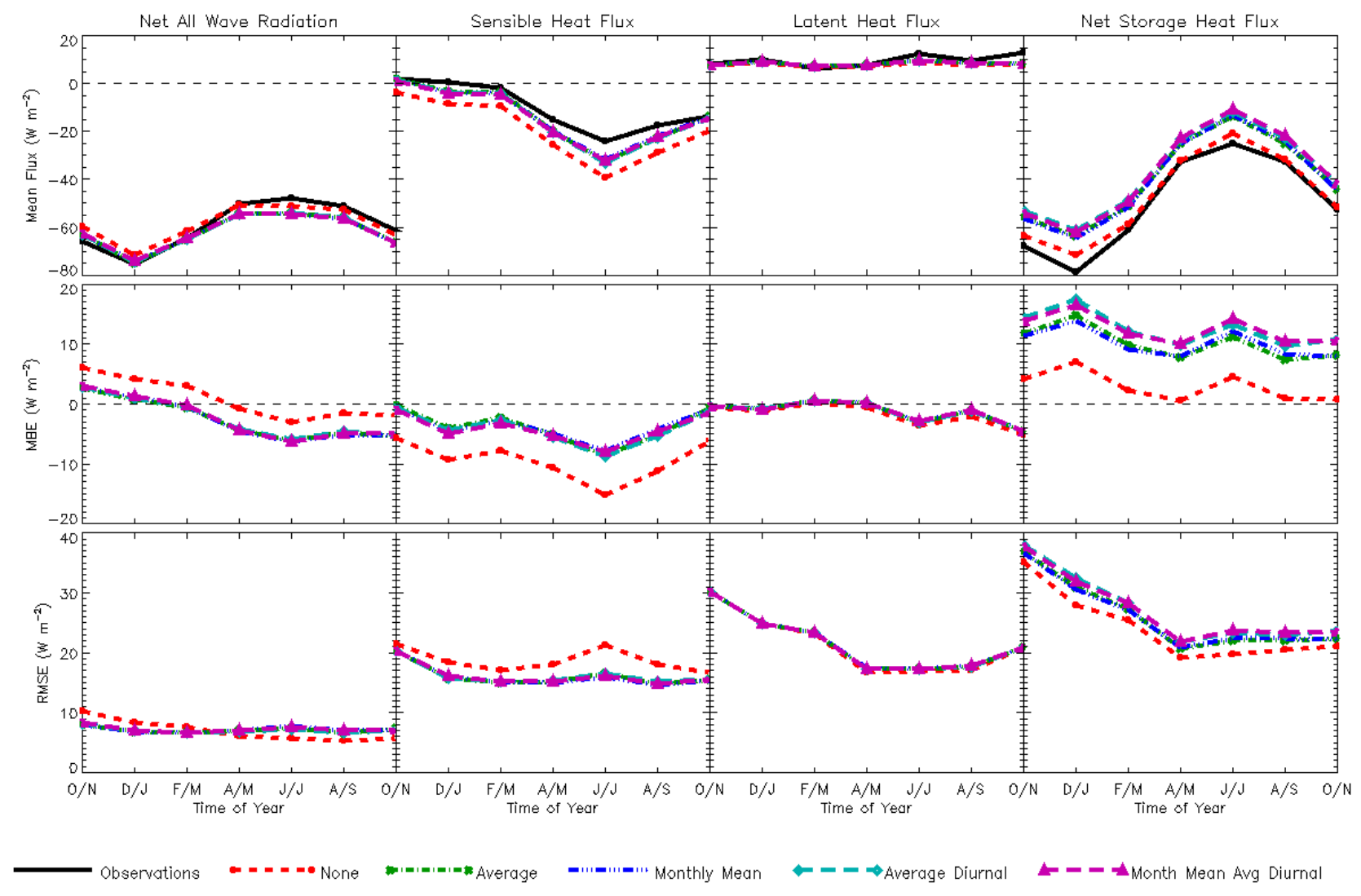

Fig. 5: Nocturnal mean modelled flux (row 1), MBE (row 2), and RMSE (row 3) for the surface fluxes determined for 485 two month periods. 

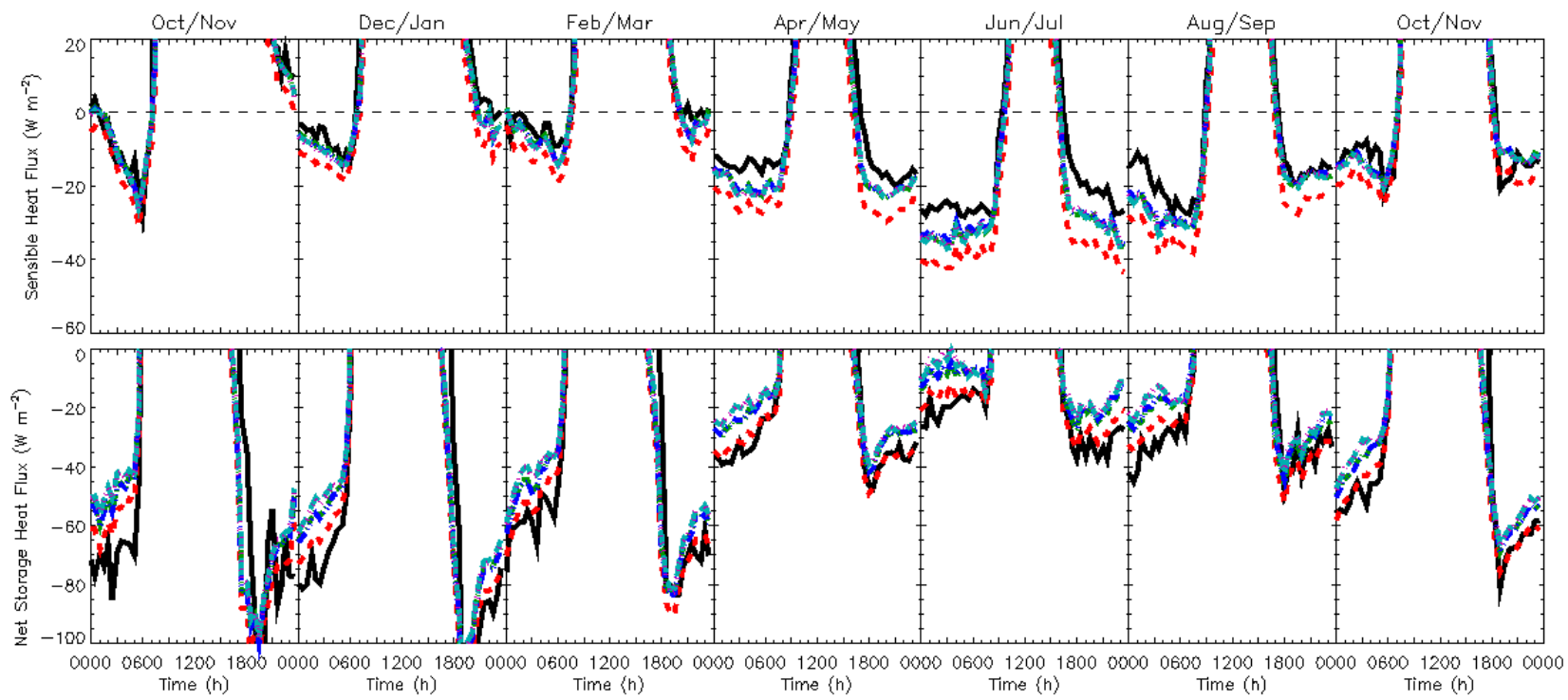

Fig. 6: Mean diurnal cycle for each 60-day period throughout the seasonal cycle, scaled to focus on the night-time 488 results, for the sensible and net storage heat fluxes. Note the scales are different for both fluxes. 